\title{
The use of a modified surgical stent in achieving keratinized peri- implant soft tissues in patients with intra-oral free flap reconstruction
}

\section{${ }^{\star}$ D. Patel${ }^{1}$, N.Patel, J.Kwok}

Figure 1 - Implants placed in osteocutaneous free flap

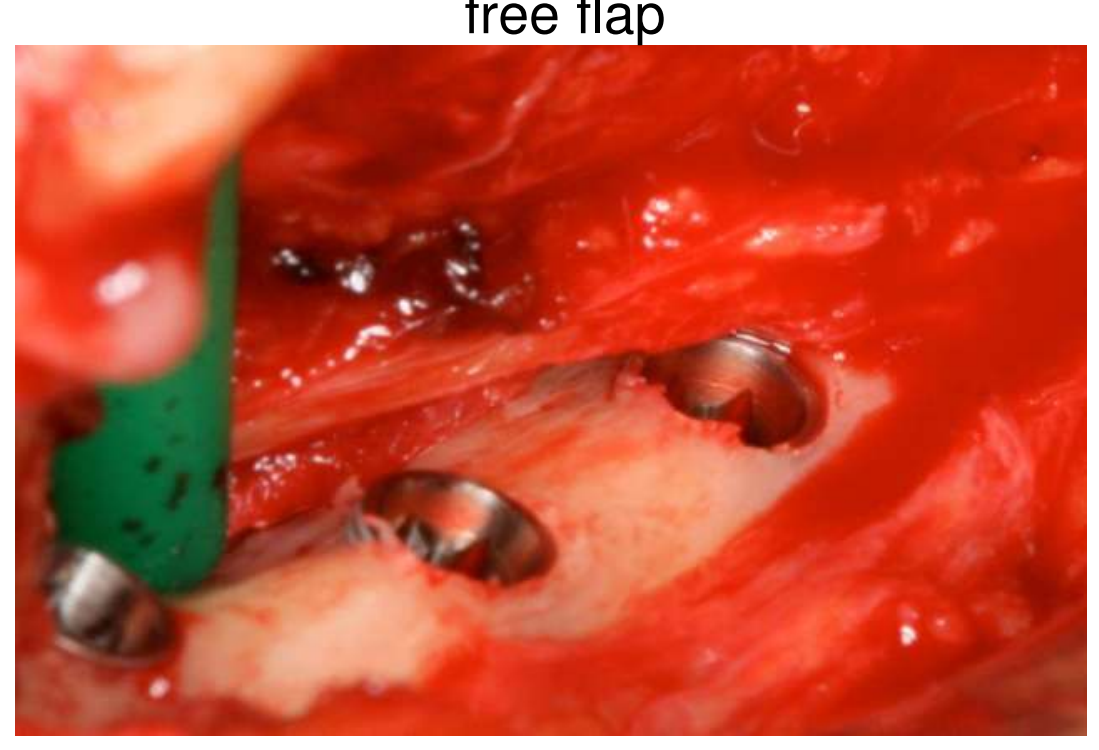

Figure 4 - Secured palatal soft tissue graft

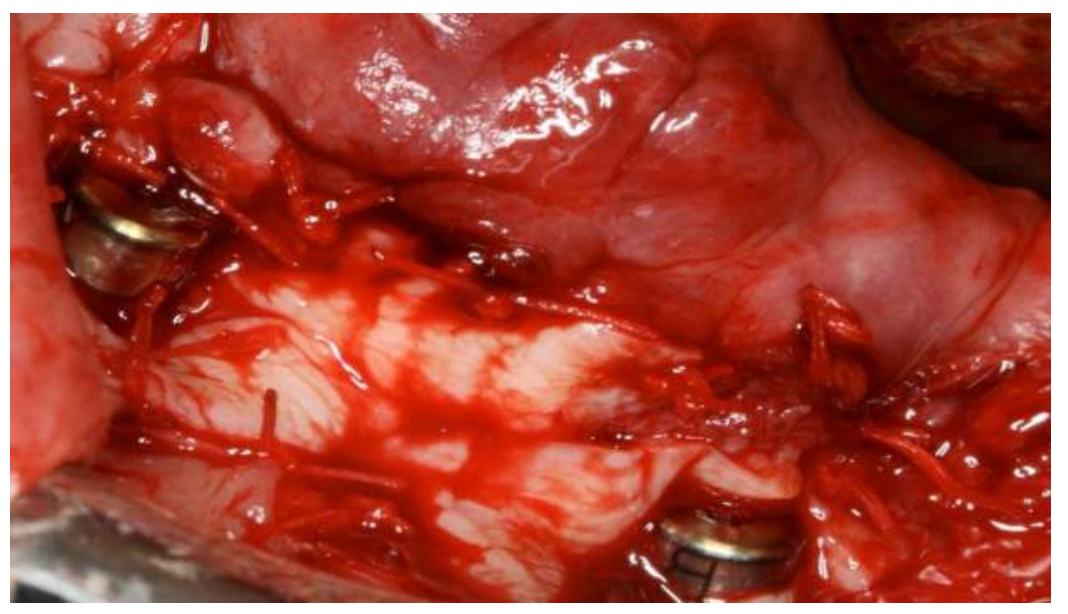

Figure 2 - Bone level impression

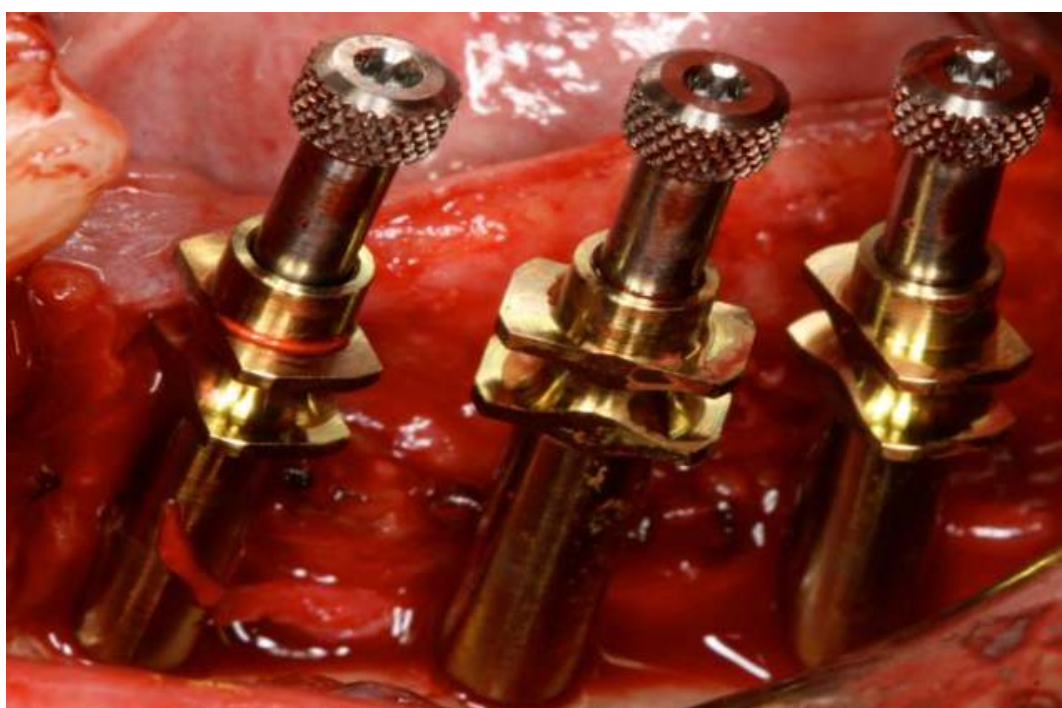

Figure 5 - Fixation stent secured in place

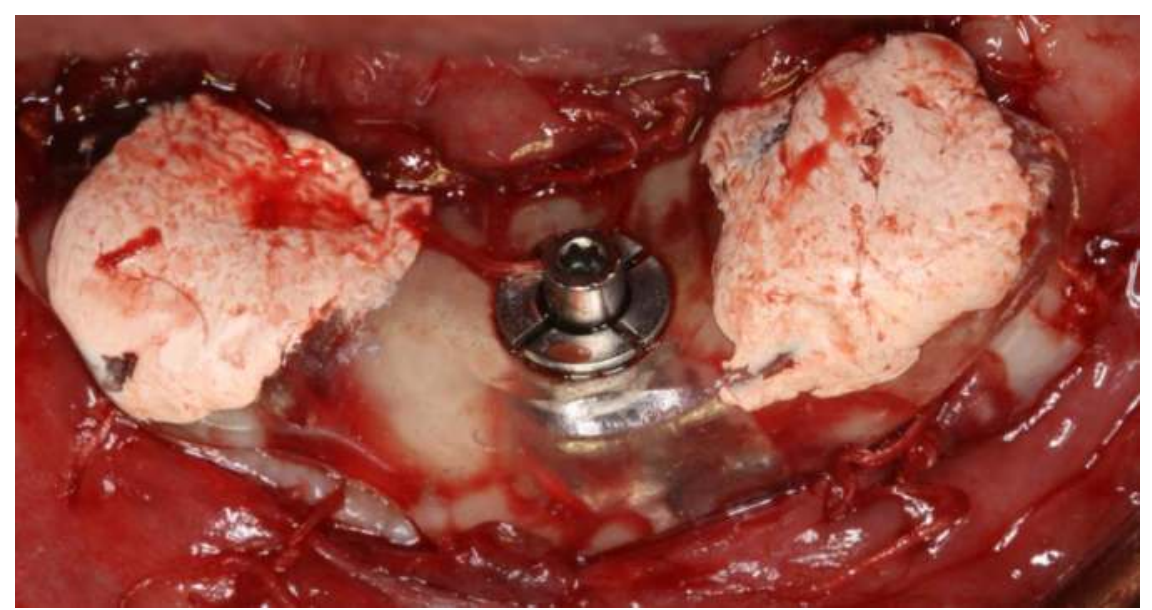

Figure 3 - Fixation Stent

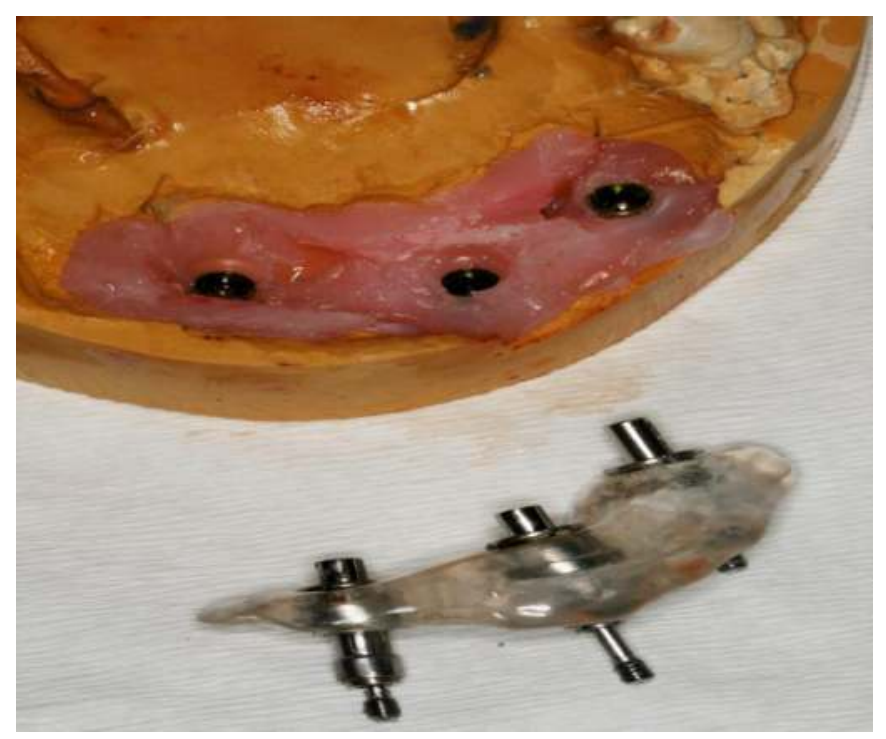

Figure 6 - Implants with keratinised soft tissue attachment

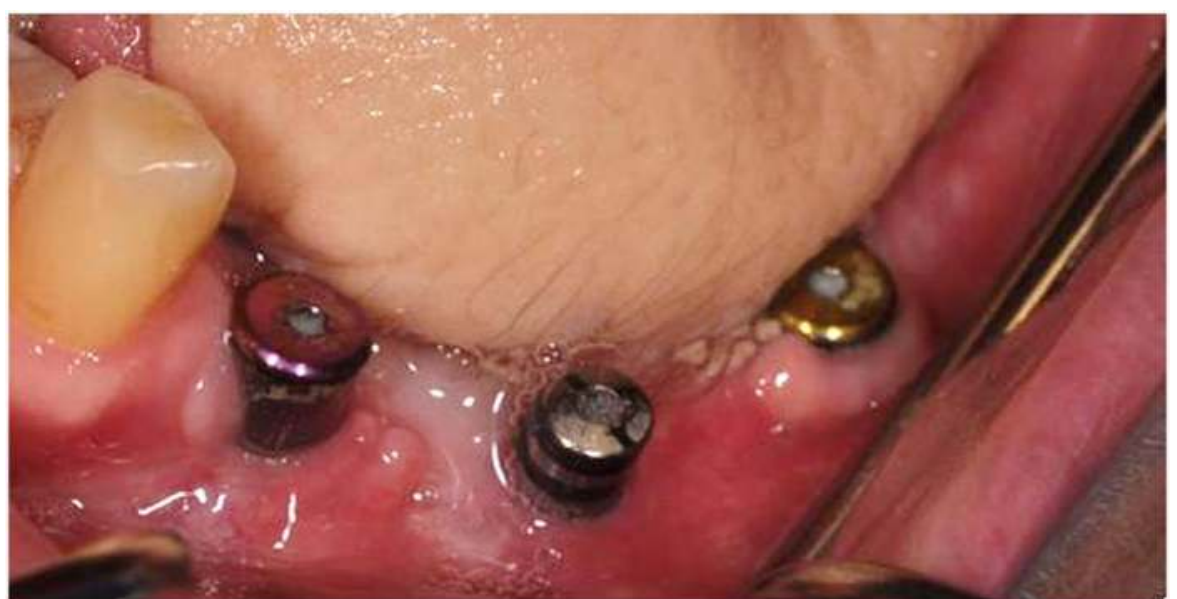

\section{Background}

Patients with large mandibular bony defects following surgery for oral cancer or trauma undergo reconstruction using osteocutaneous microvascular free flaps. These provide adequate bone and soft tissue for reconstruction; however result in altered anatomy affecting function and aesthetics. Implant supported prostheses can be used to improve both these deficits following reconstructive surgery. Although implant placement has proven successful in osteocutaneous microvascular free flaps, increased failure rates have been observed due to the cutaneous nature of peri-implant soft tissue compared with keratinised oral mucosa.

\section{Methods}

1. Initial soft tissue contouring and manipulation to increase sulcus depth is carried out through de-bulking of the skin paddle prior to implant placement. Implants are then placed and an impression is taken of the implants at bone level using an open tray technique

2. In the laboratory modelling wax or silicone is added to the stone model on the ridge to create the precise space required for the keratinised graft to be placed. The guide sleeves are then placed with the template abutment (from the Nobel Biocare ${ }^{\mathrm{TM}}$ guide system) secured to the fixture head and cured in acrylic. The thickness of keratinised tissue using this technique can be altered precisely by increasing or decreasing the thickness of acrylic on the fixation stent (figure 3).
3. Second stage surgery involves harvesting a full thickness palatal soft tissue graft and securing it around the implants which are exposed through the graft (figure 4). The fixation stent can then be retained using the template abutment and will compress the keratinized palatal graft around the implants during healing (figure 5). The fixation stent should be left in situ for 2-3 weeks until successful integration of the palatal tissue graft.

\section{Results}

As healing occurs around the stent, position and depth of sulcus tissues can be manipulated and maintained in a favourable position for prosthetic treatment. We have designed a surgical stent that facilitates precise keratinised tissue grafting and protection of the graft site using a reverse guided surgery protocol. The use of this modified stent enables precision keratinised tissue grafting, host site graft protection and stability of peri-implant tissues (figure 6).

\section{Conclusion}

This technique introduces the fixation stent adapted from the Guided Surgery protocol from Nobel Biocare ${ }^{\mathrm{TM}}$. This predictable technique results in healthy peri-implant keratinised soft tissue, thus improving long term success of the implants.

\section{References}

1. Schoen PJ, Raghoebar GM, Bouma J, et al. Rehabilitation of oralfunction in head and neck cancer patients after radiotherapy with implant-retained dentures: effects of hyperbaric oxygen therapy. Oral Oncol2007;43:379-88.

2. Weischer T, Mohr C. Implant supported mandibular telescopic prosthesesin oral cancer patients: an up to 9-year retrospective study. Int J Prosthodont2001;14:329-34. 